\title{
Signalling Pathways Implicated in Obesity Associated Cancers
}

\author{
Janice E. Drew ${ }^{*}$
}

\begin{abstract}
Metabolic Health, Rowett Institute of Nutrition and Health, University of Aberdeen, Greenburn Road, Bucksburn, ABERDEEN, AB21 9SB, Scotland, UK
\end{abstract}

\begin{abstract}
Intensive research over recent years has provided irrefutable evidence of links between obesity and the risk of an increasing number of human cancers. The predicted economic burden is causing significant concern. This has prompted investigation of the underlying mechanisms with a focus on deregulated metabolic pathways. A number of metabolic processes and associated signalling pathways are associated with the development of obesity. These include a number of interlinking pathways regulating endocrine, redox, inflammation, immunity and lipogenic processes. The identification of deregulated metabolic pathways in obesity with promotion of carcinogenesis has targeted research on the signalling molecules involved. Consequently this mini review is focused on aberrant signalling of deregulated pathways provoked by diets that lead to obesity and their role in carcinogenesis. Knowledge of the signalling molecules involved will assist in directing and establishing dietary manipulation strategies to restore metabolic health in obese individuals. Importantly the identified diversity of signalling pathways linked to obesity related cancers will permit design of more effective combinatorial and multi-targeted cancer therapies in the future.
\end{abstract}

Keywords: Obesity related cancer, metabolic signalling, signalling pathways

\section{INTRODUCTION}

The 2007 World Cancer Research Fund/American Institute for Cancer Research (WCRF/AICR) report [1] unequivocally endorsed links between obesity and increased risk of cancer. The global scale of the current obesity epidemic is causing significant concern as the projected rise in co-morbidities such as cancer are accompanied by increased economic and social burdens [2-4]. This has prompted intense research efforts to establish the determinants of increased cancer risk associated with obesity. Consequently substantial evidence has emerged establishing links between obesity and colorectal, kidney, liver/gall bladder, pancreatic, oesophageal, stomach, prostate, postmenopausal breast, endometrial, uterine and ovarian cancers, summarised in update reports from WCRF/AICR [5-7]. Accumulating evidence indicates that dietary factors such as consumption of excess calories, fat and sugars, together with sedentary behaviour and associated low energy expenditure are associated with increased cancer risk [1] (Fig. 1). Conversely, reduced calorie intake and increased fruit, vegetable and fibre intake have been linked to reduced cancer risk [1] (Fig. 1). Research on the physiological changes caused by the dietary and lifestyle trends leading to obesity has directed close scrutiny of associated deregulated signalling pathways to identify links with carcinogenesis [8-13]. Obesity is characterised by

\footnotetext{
*Address correspondence to this author at the Metabolic Health, Rowett Institute of Nutrition and Health, University of Aberdeen, Greenburn Road, Bucksburn, ABERDEEN, AB21 9SB, Scotland, UK;

Tel: +44 (0)1224 438775; Fax: +44 (0)1224 438629;

E-mail: j.drew@abdn.ac.uk
}

profound metabolic deregulation of signalling pathways that are essential to maintain homeostatic control of biological processes in cells and tissues [14-18]. Homeostatic control is fundamental in preventing the aberrant signalling that is a distinguishing characteristic of cancer cells. This review will examine the evidence linking signalling of the endocrine system [14, 15, 17]; redox regulation [19-21]; inflammatory and immune responses [16, 22-25] and lipogenesis [26] that are deregulated in obesity and linked to increased cancer risk (Fig. 2). The identification of signalling pathways linking obesity with cancer present novel targets and strategies to break the obesity cancer link.

\section{ADIPOKINE SIGNALLING PATHWAYS IMPLICATED IN CANCER}

Adipose tissue, the body's largest endocrine organ [27, 28], demonstrates significant deregulation of homeostatic control in response to consumption of high energy diets and obesity. Levels of adipose derived hormones and cytokines are altered [14, 29-31]. Two of the most abundant adipose hormones, leptin and adiponectin, regulate energy homeostasis [32]. Obesity is characterised by increased leptin and decreased adiponectin in serum with implications for a role as potential mediators in carcinogenesis linked to obesity [33-36].

The intracellular signalling leptin receptor, $O b R b$, is expressed in several tissues (colon, oesophageal, breast) associated with increased cancer risk linked to obesity [3338] and altered levels in tumours have been reported to have clinical implications [33, 35, 36, 38-41]. Roles in stimulation of cell proliferation, anti-apoptotic activity and inflammation have been demonstrated [11, 13, 42, 43]. Leptin regulates 


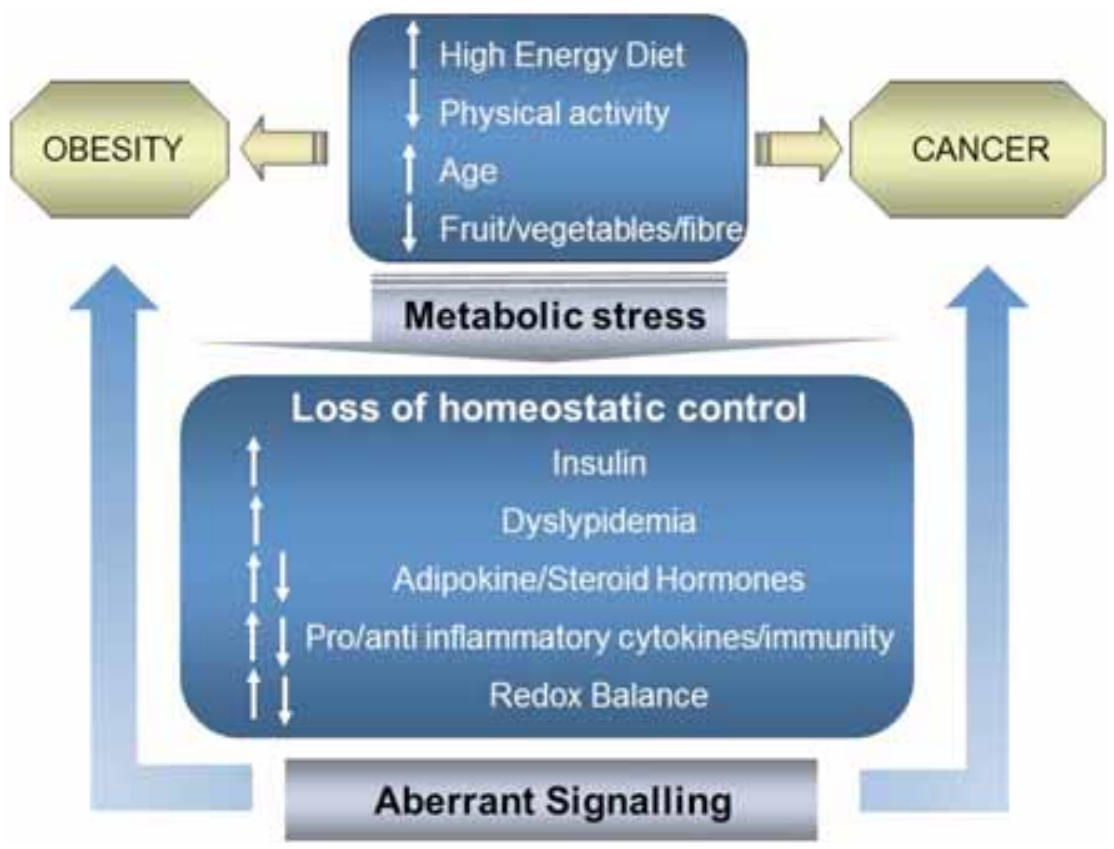

Fig. (1). Diet and lifestyle factors associated with obesity and increased cancer risk. Consumption of high energy diets, sendentary behaviour and increased age promote obesity and increased risk of cancer. Conversely, reduced calorie intake and increased fruit, vegetable and fibre intake have been linked to reduced obesity and cancer risk. Obesity is characterised by profound metabolic deregulation of signalling pathways, including those associated with the endocrine system, redox regulation, inflammation, immune responses and lipogenesis that are essential to maintain homeostatic control of biological processes in cells and tissues. Loss of homeostatic control leads to aberrant signalling that has similarities with the distinguishing characteristics of cancer cells.

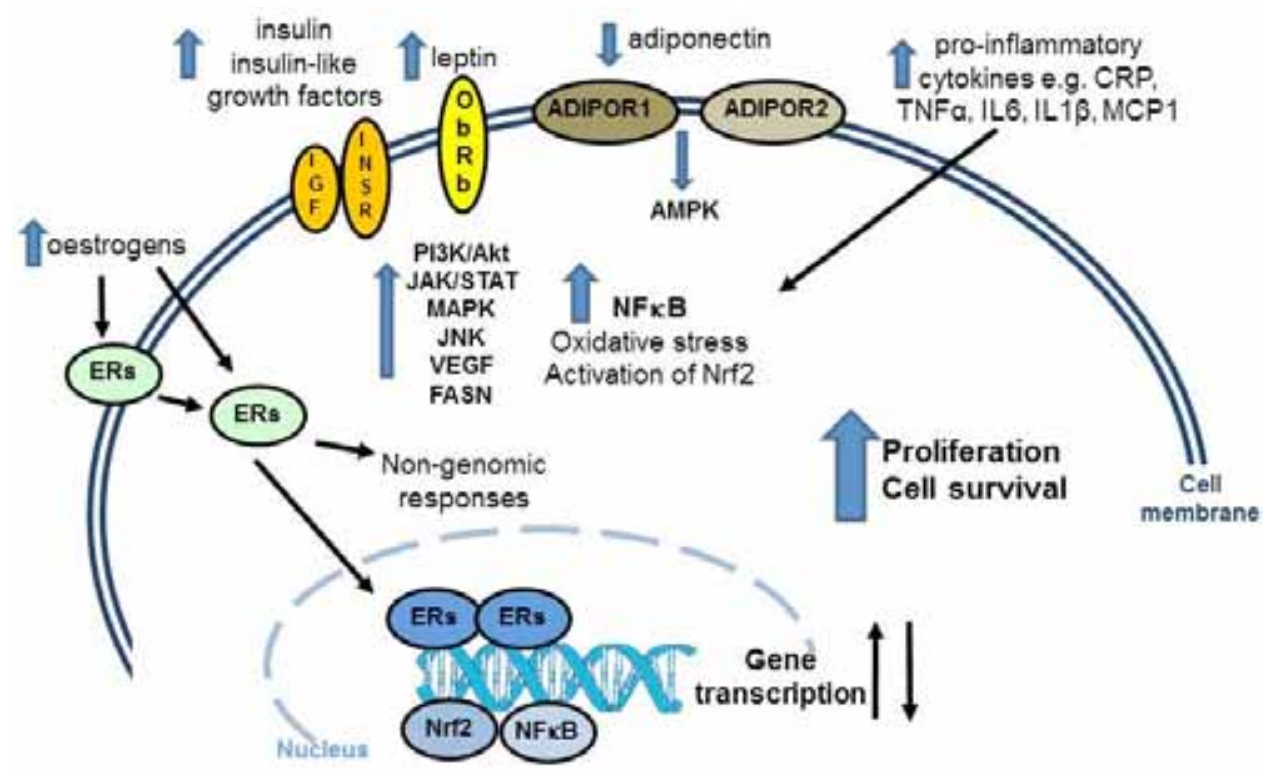

Fig. (2). Signalling pathways implicated in obesity associated cancers. Obesity leads to elevated insulin, leptin, oestrogen levels and activation of associated receptor signalling. In parallel adiponectin levels fall with concomitant reduction in adiponectin signalling. Obesity and associated deregulation of signalling pathways leads to systemic and intracellular elevation of pro-inflammatory cytokines with increased oxidative stress. Deregulation of gene transcription and signalling pathways lead to promotion of cell proliferation and survival.

several signalling pathways, JAK/STAT3 (Janus kinase/signal transducer and activator of transcription 3), PI3K/Akt (phosphatidylinositol-4,5-bisphosphate 3-kinase/vakt murine thymoma viral oncogene homolog), mTOR (mammalian target of rapamycin) and MAPK (mitogenactivated protein kinase), that present targets for modulation of carcinogenesis. Leptin is also linked to inflammatory and immune responses $[13,36,44]$, activating a number of inflammatory cytokines associated with cancer. Leptin induced cytokines such as CXCL1 (chemokine CXC motif ligand 1) $[13,41]$ and vascular perturbations leading to elevated VEGF (vascular endothelial growth factor) may be important in angiogenesis required for tumour growth [45].

Adiponectin is an abundant adipokine that is decreased with increased visceral obesity $[15,17]$. There are two adiponectin receptors, $A D I P O R 1$ and $A D I P O R 2$, mediating signalling of full-length adiponectin and the truncated 
globular portion of adiponectin [46]. These receptors are located in tissues prone to obesity related carcinogenesis and are expressed by colon and breast cancers [34, 35, 41, 42, 48]. Adiponectin stimulates phosphorylation of AMPK (5'adenosine monophosphate-activated protein kinase) to regulate cellular energy metabolism and protein synthesis [34]. Adiponectin has been demonstrated in vitro to counter leptin induced IL-6 (interleukin-6), NFאB (nuclear factor kappa-light-chain-enhancer of activated B cells) and STAT3 to reduce cell proliferation [12, 47]. Adiponectin is also reported to be associated with improved insulin regulation, blood glucose and triglyceride levels [48, 49].

\section{INSULIN AND INSULIN LIKE GROWTH FACTORS}

Inappropriate glycaemic control is a feature of obesity with consequences for development of diabetes and risk of developing cancer [50]. Hyperglycaemia in response to obesity is associated with hyperinsulinemia and the promotion of uncontrolled cell growth associated with tumorigenesis [51, 52]. Insulin signalling is initiated via transmembrane receptors, insulin (INSR) and insulin growth factor (IGF) receptor hybrids (IGF/INSR) to activate intracellular signalling cascades that ultimately influence gene transcription and cellular processes regulating growth and differentiation [53]. Insulin receptors are expressed by cells linked to obesity related carcinogenesis and in cancer [37, 41]. INSRs activate PI3K/Akt and downstream activation of mTOR and, or MAPK to regulate cell growth and mitogenesis [52]. Similarly, increased circulating insulin-like growth factor-1 (IGF-1) in obese individuals activates PI3/Akt and MAPK [52]. IGF-I is also linked to increased risk and poor prognosis for several human obesity related cancers [54]. Bioavailable IGF-I is increased by hyperinsulinemia in obese individuals as a consequence of insulin induced decreases in IGF binding proteins [52]. Notably, VEGF is also induced by elevated insulin and IGF-I levels associated with obesity [55] and aggressive cancers $[56,57]$.

\section{STEROID HORMONES}

Elevated levels of both total and free oestrogens produced by adipose tissue are linked with obesity related breast cancer [58]. Aromatase, responsible for oestrogen biosynthesis, is also elevated with obesity and can further influence the impact of oestrogens on carcinogenesis [24]. Activation of oestrogen receptors (ER) leads to canonical oestrogen response element (ERE)-dependent signalling. Oestrogen bound receptors activate EREs in promoter regions of target genes inducing transcription of genes regulating proliferation and angiogenesis [59]. Non-genomic effects following complex of ER with other receptors, such as EGFR (epidermal growth factor receptor) and IGR, leads to induction of MAPK and PI3K/Akt pathways [60]. In addition to oestrogen signalling effects on regulation of cell proliferation, mammalian cell metabolism of oestrogen generates DNA-reactive metabolites that cause DNA mutations associated with carcinogenesis [61].
Links between obesity related cancers and the androgen hormones are more equivocal. However, there are links between obesity and aggressive prostate cancer [62]. This is attributed to promiscuous androgen receptor activity between androgens and circulating cytokines (IL-6), growth factors (IGF, epidermal growth factor) and stimulation of JAK/STAT and PI3K/Akt/mTOR promoting cell survival and proliferation [63].

There has also been some interest in the extensive metabolic effects of glucocorticoids. These hormones are increased during calorie restriction and weight reduction [64] both factors associated with reduced cancer risk. Glucocorticoids activate glucocorticoid receptors to regulate transcription of genes intimately involved in regulation of apoptosis $[15,65-67]$. Cell regulation of apoptosis is crucial in preventing carcinogenesis. Another aspect of glucocorticoid function is as an anti-inflammatory [68]. The role of glucocorticoids in limiting and resolving inflammation [69] could potentially be an important pathway linked to obesity related cancer.

\section{OXIDATIVE STRESS, IMMUNITY AND INFLAMMATORY FACTORS}

The cascade of deregulated metabolic pathways deriving from over consumption of nutrients and the development of obesity ultimately overwhelm redox defences [70]. The transcription factor Nrf2 (nuclear factor (erythroid-derived 2)like 2) has been identified as a key regulator of redox balance [71] and is deregulated in obesity [49]. Deregulation of Nrf2 regulated gene transcription has implications for a host of signaling pathways that are involved in detoxifying metabolites and damaged proteins, maintenance of redox balance and DNA repair [72]. This has implications for carcinogenesis since regulation of these processes is crucial to maintaining homeostasis, DNA integrity and cell regulation.

Deregulation of metabolic pathways and the resultant oxidative stress in obesity is associated with activation of inflammatory and immune responses [73]. Immune and inflammatory responses are intimately linked with carcinogenesis [74]. This is characterised by increased NFKB activity, inappropriate production of pro-inflammatory cytokines, immune cell infiltration and disrupted tissue homeostasis $[16,22,24,75,76]$. Increases in circulating CRP (C-reactive protein), TNF $\alpha$ (tumour necrosis factor alpha), IL6, IL1 $\beta$ (interleukin-1 beta) and macrophage attractants, such as MCP-1 (monocyte chemotactic protein-1) are generated as a consequence of the production of proinflammatory cytokines from excess adipose tissue [77]. This exacerbates the deregulated inflammatory and immune responses [77]. Cross-talk between insulin, leptin and adiponectin pathways are linked to activation of inflammatory cytokines associated with carcinogenesis [13, 78]. Mediation of these responses involves recruitment of NFאB, STAT3, c-jun-NH2 terminal protein kinase (JNK) pathways [77]. NFKB is recognised as an active player in tumour associated aberrant expression of genes involved in cell proliferation, apoptosis, angiogenesis and inflammation 
[79]. It has been noted that insulin stimulated kinases, such as atypical PKCs activate NFKB [80, 81]. Atypical PKCs are overexpressed in a number of tissues associated with obesity related cancers, such as colon, kidney, liver, oesophagus and breast [82]. These interlinking pathways further emphasise the complexity in the processes of obesity associated carcinogenesis and warrant further investigation.

\section{LIPOGENIC PATHWAYS}

Obesity is associated with activation of lipogenic pathways characterised by elevated levels of fatty acid synthase (FASN) [18]. Over expression of FASN is a common event in malignancies [26]. Elevated FASN has been identified as a prognostic indicator and is linked to therapy resistant tumours [83]. Increased lipogenesis via the AKT-mTORC1 (mechanistic target of rapamycin complex 1) pathway has also been linked to hepatocellular carcinoma [84]. While mTORC1, a nutrient and insulin sensor, is also emerging as a regulator of lipid homeostasis that may be implicated in carcinogenesis [85]. This may be relevant to obesity associated liver cancer. Further research in this area may also reveal other lipogenic pathways implicated in obesity related cancer.

\section{CONCLUSION}

The metabolic deregulation associated with obesity presents a number of interconnected pathways that have implications for carcinogenesis. This knowledge can inform on potential strategies to reduce cancer risk and also direct investigation of the potential of therapies that restore metabolic regulation to improve outcomes for cancer patients. A number of studies have demonstrated that reducing dietary energy consumption can restore homeostatic regulation of metabolic pathways and reduce obesity related cancers [54,86-88]. Investigation of the presence of receptors for the various signalling molecules and hormones deregulated in obesity in tissues prone to obesity related cancers may inform about the potential to manipulate these signalling pathways to prevent cancer. There has been limited study of the potential to influence outcomes for cancer patients using therapeutics directed at alleviating the disorders associated with the metabolic syndrome [89-91]. Diabetic therapies have been linked to reduction of some cancers, but not others [90]. Greater understanding of the interplay of deregulated metabolic pathways in carcinogenesis will be essential in directing appropriate and more effective therapeutic strategies for individuals and contribute to producing multi-targeted approaches to reduce therapy resistance. Thus further studies are warranted to determine appropriate strategies to combat obesity related cancer and develop novel combination therapies and multi-targeted approaches to provide more effective treatment of cancer patients.

\section{CONFLICT OF INTEREST}

The authors confirm that this article content has no conflicts of interest.

\section{ACKNOWLEDGEMENTS}

Grant support: The Scottish Government's Rural and Environment Science and Analytical Services Division. Declaration of interest: The author declares that there is no conflict of interest.

\section{REFERENCES}

[1] World Cancer Research Fund/American Institute for Cancer Research. Food Nutrition, Physical Activity, and the Prevention of Cancer: a Global Perspective. Washington DC: AICR 2007.

[2] Butland B, Jebb S, Kopelman P, et al. Tackling Obesities: Future Choices-Project Report. $2^{\text {nd }}$ Ed. Government; Office for Science 2007. Available: http: //www.bis.gov.uk/assets/foresight/d ocs/obesity/17.pdf

[3] Wang YC, McPherson K, Marsh T, Gortmaker SL, Brown M. Health and economic burden of the projected obesity trends in the USA and the UK. Lancet 2011; 378: 815-25.

[4] Keaver L, Webber L, Dee A, et al. Application of the UK Foresight Obesity Model in Ireland: The health and economic consequences of projected obesity trends in Ireland. PLoS One 2013; 8: e79827.

[5] World Cancer Research Fund/American Institute for Cancer Research. Continuous Update Project Breast Cancer 2010 Report Washington DC: AICR 2010.

[6] World Cancer Research Fund/American Institute for Cancer Research. Continuous Update Project Colorectal Cancer 2011 Report Washington DC: AICR 2011.

[7] World Cancer Research Fund/American Institute for Cancer Research. Continuous Update Project Pancreatic Cancer 2012 Report. Washington DC: AICR 2012.

[8] Aparicio T, Guileau S, Goiot H, et al. Leptin reduces the development of the initial precancerous lesions induced by azoxymethane in the rat colonic mucosa. Gastroenterol 2004; 126 : 499-510.

[9] Kiunga GA, Raju J, Sabljic N, Bajaj G, Good CK, Bird RP. Elevated insulin receptor expression in experimentally induced colonic tumours. Cancer Lett 2004; 211: 145-53.

[10] Aparicio T, Kotelevets L, Tsocas A, et al. Leptin stimulates the proliferation of human colon cancer cells in vitro but does not promote the growth of colon cancer xenografts in nude mice nor intestinal tumourigenesis in ApcMin/+ mice. Gut 2005; 54: 113645.

[11] Fenton JI, Hursting SD, Perkins SN, Hord NG. Leptin induces an Apc genotype-associated colon epithelial cell chemokine production pattern associated with macrophage chemotaxis and activation. Carcinogenesis 2007; 28: 455-64.

[12] Fenton JI, Birmingham JM, Hursting SD, Hord NG. Adiponectin blocks multiple signalling cascades associated with leptin-induced cell proliferation in Apc Min/+colon epithelial cells. Int J Cancer 2008; 122: 2437-45.

[13] Padidar S, Farquharson AJ, Williams LM, et al. Leptin upregulates pro-inflammatory cytokines in discrete cells within mouse colon. J Cell Physiol 2011; 226: 2123-30.

[14] Ostlund RE Jr, Yang JW, Klein S, Gingerich R. Relation between plasma leptin concentration and body fat, gender, diet, age, and metabolic covariates. J Clin Endocrinol Metab 1996; 81: 3909-13.

[15] Hu E, Liang P, Spiefelman BM. AdipoQ is a novel adipose-specific gene dysregulated in obesity. J Biol Chem 1997; 271: 10697-703.

[16] Wellen KE, Hotamisligil GS. Obesity-induced inflammatory changes in adipose tissue. J Clin Invest 2003; 112: 1785-8.

[17] Yildiz BO, Suchard MA, Wong ML, McCann SM, Licinio J. Alterations in the dynamics of circulating grehlin, adiponectin, and leptin in human obesity. Proc Natl Acad Sci USA 2004; 101: 10434-39.

[18] Berndt J, Kovacs P, Ruschke K, et al. Fatty acid synthase gene expression in human adipose tissue: association with obesity and type 2 diabetes. Diabetologia 2007; 50: 1472-80.

[19] Vincent HK, Taylor AG. Biomarkers and potential mechanisms of obesity-induced oxidant stress in humans. Intl J Obes 2006; 30: 400-18.

[20] Esposito K, Ciotola M, Schisano B, et al. Oxidative stress in the metabolic syndrome. J Endocrinol Invest 2006; 29: 791-5. 
[21] Pihl E, Zilmer K, Kullisaar T, Kairane C, Magi A, Zilmer M. Atherogenic inflammatory and oxidative stress markers in relation to overweight values in male former athletes. Int J Obes 2006; 30: 141-6.

[22] Hotamisligil GS, Shargill NS, Spiegelman BM. Adipose expression of tumor necrosis factor-alpha: direct role in obesity-linked insulin resistance. Science 1993; 259: 87-91.

[23] Olefsky JM, Glass CK. Macrophages, inflammation, and insulin resistance. Ann Rev Physiol 2010; 72: 219-46.

[24] Morris PG, Hudis CA, Giri D, et al. Inflammation and increased aromatase expression occur in the breast tissue of obese women with breast cancer. Cancer Prev Res Phila 2011; 4: 1021-9.

[25] Arcidiacono B, Iiritano S, Nocera A, et al. Inflammation insulin resistance and cancer risk: an overview of the pathogenetic mechanisms. Exp Diabetes Res 2012; 2012: 789174.

[26] Menendez JA, Lupu R. Fatty acid synthase and the lipogenic phenotype in cancer pathogenesis. Nat Rev Cancer 2007; 7: 763 77.

[27] Kershaw EE, Flier JS. Adipose tissue as an endocrine organ. J Clin Endocrinol Metab 2004; 89: 2548-56.

[28] Cinti S. The adipose organ. Prostaglandins Leukot Essent Fatty Acids 2005; 73: 9-15.

[29] Fatouros IG, Tournis S, Leontsini D, et al. Leptin and adiponectin responses in overweight inactive elderly following resistance training and detraining are intensity related. J Clin Endocrinol Metab 2005; 90: 5970-7.

[30] Al-Lahham SH, Roelofsen H, Priebe M, et al. Regulation of adipokine production in human adipose tissue by propionic acid. Eur J Clin Invest 2010; 40: 401-7.

[31] Dutheil F, Lesourd B, Courteix D, Chapier R, Dore E, Lac G. Blood lipids and adipokines concentrations during a 6-month nutritional and physical activity intervention for metabolic syndrome treatment. Lipids Health Dis 2010; 9: 148.

[32] Friedman JM, Halaas JL. Leptin and the regulation of body weight in mammals. Nature 1998; 395: 763-70.

[33] Garofalo C, Koda M, Cascio S, et al. Increased expression of leptin and the leptin receptor as a marker of breast cancer progression: possible role of obesity-related stimuli. Clin Cancer Res 2006; 12: 1447-53.

[34] Kelesidis I, Kelesidis T, Mantzoros CS. Adiponectin and cancer: a systematic review. Br J Cancer 2006; 94: 1221-5.

[35] Howard JM, Cathcart MC, Healy L, et al. Leptin and adiponectin receptor expression in oesophageal cancer. Br J Surg 2014; 101: 643-52.

[36] Abolhassani M, Aloulou N, Chaumett MT, et al. Leptin receptorrelated immune response in colorectal tumors: the role of colonocytes and interleukin-8. Cancer Res 2008; 68: 9423-32.

[37] Drew JE, Farquharson AJ, Padidar S, et al. Insulin, leptin and adiponectin receptors in colon: regulation relative to differing body adiposity independent of diet and in response to dimethylhydrazine. Amer J Physiol - Gastrointest Liver Physiol 2007; 293: G682-91.

[38] Uddin S, Bavi P, Hussain AR, et al. Leptin receptor expression in Middle Eastern colorectal cancer and its potential clinical implication. Carcinogenesis 2009; 30: 1832-40.

[39] Paik SS, Jang SM, Jang KS, Lee KH, Choi D, Jang SJ. Leptin expression correlates with favorable clinicopathologic phenotype and better prognosis in colorectal adenocarcinoma. Ann Surg Oncol 2009; 16: 297-303.

[40] Stachowicz M, Mazurek U, Nowakowska-Zajdel E, Niedworok E, Fatyga E, Muc-Wierzgon M. Leptin and its receptors in obese patients with colorectal cancer. J Biol Regul Homeost Agents 2010; 24: 287-95.

[41] Farquharson AJ, Steele RJ, Carey FA, Drew JE. Novel multiplex method to assess insulin, leptin and adiponectin regulation of inflammatory cytokines associated with colon cancer. Mol Biol Reports 2012; 39: 5727-33.

[42] Hoda MR, Keely SJ, Bertelsen LS, Junger WG, Dharmasena D, Barrett KE. Leptin acts as a mitogenic and antiapoptotic factor for colonic cancer cells. Br J Surg 2007; 94: 346-54.

[43] Ogunwobi OO, Beales IL. Cyclo-oxygenase-independent inhibition of apoptosis and stimulation of proliferation by leptin in human colon cancer cells. Dig Dis Sci 2007; 52: 1934-45.

[44] Fantuzzi G, Faggioni R. Leptin in regulation of immunity, inflammation and hematopoiesis. J Leukocyte Biol 2000; 68: 4376.
[45] Hursting SD, Hursting MJ. Growth signals, inflammation, and vascular perturbations: mechanistic links between obesity, metabolic syndrome, and cancer. Arterioscler Thromb Vasc Biol 2012; 32: 1766-70.

[46] Yamauchi T, Kamon J, Ito Y, et al. Cloning of adiponectin receptors that mediate antidiabetic metabolic effects. Nature 2003; 423: 762-9.

[47] Fenton JI, Birmingham JM. Adipokine regulation of colon cancer: adiponectin attenuates interleukin-6-induced colon carcinoma cell proliferation via STAT-3. Mol Carcinog 2010; 49: 700-9.

[48] Knobler H, Benderly M, Boyko V, et al. Adiponectin and the development of diabetes in patients with coronary artery disease and impaired fasting glucose. Eur J Endocrinol 2006; 154: 87-92.

[49] Schneider KS, Chan JY. Emerging role of Nrf2 in adipocytes and adipose biology. Adv Nutr 2013; 4: 62-6.

[50] Andersen DK. Diabetes and cancer: placing the association in perspective. Curr Opin Endocrinol Diabetes Obes 2013; 20: 81-6.

[51] Durai R, Yang W, Gupta S, Seifalian AM, Winslet MC. The role of the insulin-like growth factor system in colorectal cancer: review of current knowledge. Int J Colorectal Dis 2005; 20: 203-20.

[52] Pollak M. Insulin and insulin-like growth factor signalling in neoplasia. Nat Rev Cancer 2008; 8: 915-28.

[53] Belfiore A, Frasca F, Pandini G, Sciacca L, Vigneri R. Insulin receptor isoforms and insulin receptor/insulin-like growth factor receptor hybrids in physiology and disease. Endocr Rev 2009; 30: 586-23.

[54] Hursting SD, Smith SM, Lashinger LM, Harvey AE, Perkins SN. Calories and carcinogenesis: lessons learned from 30 years of calorie restriction research. Carcinogenesis 2010; 31: 83-9.

[55] Loebig M, Klement J, Schmoller A, et al. Evidence for a relationship between VEGF and BMI independent of insulin sensitivity by glucose clamp procedure in a homogenous group healthy young men. PLoS One 2010; 59: e12610.

[56] Cao D, Hou M, Guan YS, Jiang M, Yang Y, Gou HF. Expression of HIF-1alpha and VEGF in colorectal cancer: association with clinical outcomes and prognostic implications. BMC Cancer 2009; 9: 432.

[57] Liu Y, Tamimi RM, Collins LC, et al. The association between vascular endothelial growth factor expression in invasive breast cancer and survival varies with intrinsic subtypes and use of adjuvant systemic therapy: results from the Nurses' Health Study. Breast Cancer Res Treat 2011; 129: 175-84.

[58] Rock CL, Pande C, Flatt SW, et al. Favorable changes in serum oestrogens and other biologic factors after weight loss in breast cancer survivors who are overweight or obese. Clin Breast Cancer 2013; 13: 188-5

[59] Péqueux C, Raymond-Letron I, Blacher S, et al. Stromal oestrogen receptor- $\alpha$ promotes tumor growth by normalizing an increased angiogenesis. Cancer Res 2012; 72: 3010-9.

[60] Kato S, Endoh H, Masuhiro Y, et al. Activation of the oestrogen receptor through phosphorylation by mitogen-activated protein kinase. Science 1995; 270: 1491-4.

[61] Cavalieri EL, Rogan EG. Unbalanced metabolism of endogenous oestrogens in the etiology and prevention of human cancer. J Steroid Biochem Mol Biol 2011; 125: 169-80.

[62] Jayachandran J, Bañez LL, Aronson WJ, et al. Obesity as a predictor of adverse outcome across black and white race: results from the Shared Equal Access Regional Cancer Hospital (SEARCH) Database. Cancer 2009; 115: 5263-71.

[63] Lonergan PE, Tindall DJ. Androgen receptor signaling in prostate cancer development and progression. J Carcinog 2011; 10: 20.

[64] Fontana L. Neuroendocrine factors in the regulation of inflammation: excessive adiposity and calorie restriction. Exp Gerontol 2009; 44: 41-5

[65] Wang Z, Malone MH, He H, McColl KS, Distelhorst CW. Microarray analysis uncovers the induction of the proapoptotic BH3-only protein Bim in multiple models of glucocorticoidinduced apoptosis. J Biol Chem 2003; 278: 23861-67.

[66] Lu NZ, Collins JB, Grissom SF, Cidlowski JA. Selective regulation of bone cell apoptosis by translational isoforms of the glucocorticoid receptor. Mol Cell Biol 2007; 27: 7143-60.

[67] Schlossmacher G, Platt E, Davies A, Meredith S, White A. Glucocorticoid receptor-mediated apoptosis in small-cell lung cancer requires interaction with BCL2. Endocr Relat Cancer 2013; 20: 785-95. 
[68] Rhen T, Cidlowski JA. Antiinflammatory Action of Glucocorticoids - New Mechanisms for Old Drugs. N Engl J Med 2005; 353: 1711-23

[69] Sapolsky RM, Romero LM, Munck AU. How do glucocorticoids influence stress responses? Integrating permissive, suppressive, stimulatory and preparative actions. Endocrine Rev 2000; 21: 5589.

[70] Bes-Rastrollo M, Martínez-González MA, Sánchez-Villegas A, de la Fuente Arrillaga C, Martínez JA. Association of fiber intake and fruit/vegetable consumption with weight gain in a Mediterranean population. Nutrition 2006; 5: 504-11

[71] Nguyen T, Sherratt PJ, Pickett CB. Regulatory mechanisms controlling gene expression mediated by the antioxidant response element. Annu Rev Pharmacol Toxicol 2003; 43: 233-60.

[72] Giudice A, Montella M. Activation of the Nrf2-ARE signaling pathway: a promising strategy in cancer prevention. Bioessays 2006; 28: 169-81.

[73] Hotamisligil GS. Inflammation and metabolic disorders. Nature 2006: 444: 860-7.

[74] Mantovani A, Allavena P, Sica A, Balkwill F. Cancer-related inflammation. Nature 2008; 454: 436-44.

[75] McLean MH, Murray GI, Stewart KN, et al. The inflammatory microenvironment in colorectal neoplasia. PLoS One 2011; 6: e15366.

[76] Subbaramaiah K, Morris PG, Zhou XK, et al. Increased levels of COX-2 and prostaglandin E2 contribute to elevated aromatase expression in inflamed breast tissue of obese women. Cancer Discov 2012; 2: 356-65.

[77] Shoelson SE, Herrero L, Naaz A. Obesity, inflammation, and insulin resistance. Gastroenterol 2007; 132: 2169-80.

[78] Schenk S, Saberi M, Olefsky JM. Insulin sensitivity: modulation by nutrients and inflammation. J Clin Invest 2008; 118: 2992-3002.

[79] Baker RG, Hayden MS, Ghosh S. NF- KB, inflammation, and metabolic disease. Cell Metab 2011; 13: 11-22

[80] Copps KD, White MF. Regulation of insulin sensitivity by serine/threonine phosphorylation of insulin receptor substrate proteins IRS1 and IRS2. Diabetologia 2012; 55: 2565-82.
[81] Diaz-Meco MT, Moscat J. The atypical PKCs in inflammation: NF- $\kappa \mathrm{B}$ and beyond. Immunol Rev 2012; 246: 154-67.

[82] Parker PJ, Justilien V, Riou P, Linch M, Fields AP. Atypical protein kinase $\mathrm{Cl}$ as a human oncogene and therapeutic target. Biochem Pharmacol 2014; 88: 1-11.

[83] Liu H, Wu X, Dong Z, et al. Fatty acid synthase causes drug resistance by inhibiting TNF- $\alpha$ and ceramide production. J Lipid Res 2013; 54: 776-85.

[84] Calvisi DF, Wang C, Ho C, et al. Increased lipogenesis, induced by AKT-mTORC1-RPS6 signaling, promotes development of human hepatocellular carcinoma. Gastroenterol 2011; 140: 1071-83.

[85] Ricoult SJ, Manning BD. The multifaceted role of mTORC1 in the control of lipid metabolism. EMBO Rep 2013; 14: 242-51.

[86] Ashrafian H, Ahmed K, Rowland SP, et al. Metabolic surgery and cancer: protective effects of bariatric procedures. Cancer 2011; 117: 1788-99.

[87] Harvie M, Wright C, Pegington M, et al. The effect of intermittent energy and carbohydrate restriction v. daily energy restriction on weight loss and metabolic disease risk markers in overweight women. Br J Nutr 2013; 16: 1-14.

[88] Xie L, Wang W. Weight control and cancer preventive mechanisms: role of insulin growth factor-1-mediated signaling pathways. Exp Biol Med Maywood 2013; 238: 127-32.

[89] Pollak MN. Investigating metformin for cancer prevention and treatment: the end of the beginning. Cancer Discov 2012; 2: 77890 .

[90] Onitilo AA, Stankowski RV, Berg RL, et al. Type 2 diabetes mellitus, glycemic control, and cancer risk. Eur J Cancer Prev 2014; 23: 134-40.

[91] Sankaranarayanapillai M, Zhang N, Baggerly KA, Gelovani JG. Metabolic shifts induced by fatty acid synthase inhibitor orlistat in non-small cell lung carcinoma cells provide novel pharmacodynamic biomarkers for positron emission tomography and magnetic resonance spectroscopy. Mol Imaging Biol 2013; 15: $136-47$.

() Janice E. Drew; Licensee Bentham Open.

This is an open access article licensed under the terms of the Creative Commons Attribution Non-Commercial License (http://creativecommons.org/licenses/by-nc/3.0/) which permits unrestricted, non-commercial use, distribution and reproduction in any medium, provided the work is properly cited. 